\title{
EXTRACTION AND EVALUATION OF PHYTOCHEMICALS FROM BANANA PEELS (MUSa sapientum) AND BANANA PLANTS (Musa paradisiaca)
}

Asif Ahmed Kibria ${ }^{1 *}$, Kamrunnessa², Md. Mahmudur Rahman³ ${ }^{3}$ Annanya Kar ${ }^{4}$

Department of Nutrition and Food Engineering

Daffodil International University

Shobhanbagh, Dhaka, Bangladesh

Corresponding Author Email: ahmed.kibria587@gmail.Com

\section{Doi : 10.2478/mjhr-2019-0005}

\section{ABSTRACT}

Banana plants (Musa paradaisica) and banana peels (Musa sapientum) two of same genus Musa are grown in worldwide and consumed as ripe fruit or used for culinary purpose. All parts of the banana plants have medicinal applications. The aim of the present study was detection of phytochemicals from this two types of samples and find out some viable phytochemicals which might be used as food additives after commercial purification. These two types of samples banana plants and banana peels were collected from local area of sobhanbagh near Daffodil International University. Samples were washed and dried in room temperature and grinded in pestle. Then $25 \mathrm{gm}$ of grinded samples were soaked in $75 \mathrm{ml}$ of $70 \%$ methanol, ethanol, acetone and $0.9 \% \mathrm{NaCl}$ solution for 72 hours. Then all the extracts of banana peels and banana plants were detected by standard protocol. Flavonoids, carbohydrates, reducing sugar, tannins, saponins, anthraquinones, steroids, glycosides, phytosterols, phenols, terpenoids, were detected from those extracts. Negative and positive result of presence of phytochemicals were detected by the observing of color change. Banana peels and banana plant extracts were showed maximum result in ethanolic extracts. The present study showed qualitative analysis of phytochemicals content existence in banana peels and banana plants extracts. The study also discussed the application of some phytochemicals in food industry.

Keywords: Banana peels and Plants, Sample preparation, Screening of Phytochemicals.

\section{INTRODUCTION}

The traditional herbal medicine is popular amongst rural dwellers worldwide. About 3.4 billion people in developing countries in world depend on plant based traditional medicines. Natural products have been an integral part of the ancient traditional medicine system [1]. According to the world health organization (WHO), a medicinal plant is any plant, which is one or more organs, substances that contains, be used for therapeutic purpose. Plant will have its part including leaves, roots, rhizomes, stamps, and barks and therefore contains chemical components. These non-nutrient plant chemical compounds and bioactive compounds which were often referred to as phytochemicals [2-5].

Phytochemical compounds are those types of compounds that are remains in various types of plant source. It is worth repeating that the evolution of modern medicine derived from applying scientific principles to herbalism and to this day plants derived compounds provide the skeleton for constructing molecules with the abilities to cure many diseases. In recent times applications to phytochemicals have extended into other areas especially nutraceuticals and functional foods [6]. Plants are still major sources of the foods worldwide and phytochemicals can play a significant role in modern food and pharmaceutical industries. The health benefits of phytochemicals is essentials as many phytochemicals have been reported to illicit both positive and negative biological effects. In recent times some evidence for the role of specific plant food phytochemicals in protecting against the onset of disease such as cancer and heart disease has been put forward [7]. The use of phytochemical substance as a food additives required that this substance is not toxic which prefers recommended level of use. Specific role of chemical characteristics of vitamin, mineral, amino acids, and other phytochemicals which can be used to improve nutritional food staff profile. The common practice of fruit juice, canned vegetables, and bakery products snacks and milk included in food formulations of balance during processing. The fortification of food additives used for producing quality food [9]. Plant and fruits have sweetening properties, which are a great source of phytochemicals. Many of these sweetning agents are not directly sugar, but protein. Monellin, Thaumatin, Brazzein, Pentadin, Miraculin, and Mabilin are plant origin sweetening properties. Many phytochemicals also used as coloring substance in the time of food processing. They adjust correct food coloration during processing and storage. Anthrocyaanins, betalains, chlorophylls and carotenoids are the coloring substance [10-13].

\subsection{Banana peels (Musa sapientum) and Banana plants (Musa Paradisiaca)}

The banana and plantains (Musa spp.) which belongs to the family musaceae are one of the most important subsistence crops [14-15]. Bangladesh is an agricultural country. More than $80 \%$ people directly depend on agriculture. The United Nations Food and Agriculture Organization ranked banana as the world's fourth most important crops [16].Bangladesh ranks 14th among Top 20 banana prucing countries in the world [17]. The country yearly produces 1 million tons of banana and it also a nutritious fruits crops which have grown many tropical area

Over Bangladesh, According to BBS-2009-2010 the total production of banana were 818254 metric tons. Banana is one of the most important fruit and crash crop which grown in year round. [18]. Major districts of cultivated area is Narshingdi, Gazipur, Rangpur, Bogra, Nator, pabna, noakhali,khulna in the country [19]. Though banana production in worldwide is 30 million per year peels constitute up to $30 \%$ of the ripe fruit. Utilization of banana waste include that, are the protein production by biotechnological process [20], ethanol, alpha-amylase and cellulose. Banana peel contains a lot of phytochemicals and phytonutrient compounds mainly antioxidant. Ripend banana peel contains various types of compounds such as anthocyanins, delphinidin, cyaniding, and catecholamines. Carotenoids, beta- carotene, alpha- carotene have been identified by different methods [21-27].

Various part of the banana plants like roots, leaves, flowers have used different types of medicinal purposes for example, leaf juice is use to treated flesh winds cuts and insects bites and leaves acts as an arbortifacient. Even the sap of the plants used to treatment of diarrhea, dysentery, hysteria and epilepsy. The root is used to treat general disease and anemia. It also has been notified to use as antiscorbutic, aphrodisiac, and diuretic [28]. Banana stem extracts had been suggested to be beneficial properties for the treatment of hypeoxaluricurolithiasis [29], high blood pressure and kidney disease. According to BBS 2009-2010 around 133305 acre were cultivated by banana plant and 818254 metric tons of banana were produced. Roots, flesh, even all the body of the banana plants are useable, but in our country huge amount of banana tree have thrown after collecting the banana fruits. This banana when cut down it causes the pollution of environment [[30].

\section{MATERIALS AND METHODS}

All experiments were performed in the Process lab of Department of Nutrition and Food Engineering Daffodil International University.

\subsection{Collection of sample or plants materials}

Banana peels and the banana plants were collected from the local area of market and sobhanbagh near the daffodil international university. A huge amount of banana are sell in everywhere in Dhaka city and the banana peel are thrown by the people after eating the banana fruit portion. On the other hand banana plants are grown everywhere in Bangladesh. Banana plants are cutting by the farmer and thrown away after taking the fruit. The collected samples were available in the Dhaka city and this types of materials are mentioned as a waste materials. So that it is easily collected from the local area at Dhaka city.

\subsection{Sample Preparation and procedure}

The collected samples were washed properly and keep it room temperature for some time for dry. The samples were cut into small pieces and blended by electronic blender and then pestle and grinded by mortar for fine particles. The grinded two types of samples were soaked with prepared $70 \%$ methanol, 
ethanol, acetone and $0.9 \% \mathrm{Nacl}$ aqueous solvents. The extracts of samples were prepared $25 \mathrm{mg}$ in $75 \mathrm{ml}$ of solvents in conical flask for the $1: 3$ ratios. Another solvent $0.9 \% \mathrm{NaCl}$ was taken $75 \mathrm{ml}$ into a conical flask and $25 \mathrm{gm}$ of extracts and mixed well. The aluminum foil paper were used to seal the conical flask and marked by permanent marker for identifying. Four types of extracts were kept at 72 hours or 3 days at room temperature. After 72 hours all the extracts were sieved with a thin cloth and all the aqueous extracts taken into separate conical flask and sealed by aluminum foil paper. Then marked by a permanent marker. The extracts were used for the detection of phytochemical analysis.

\subsection{Screening of phytochemicals compound}

To identify the photochemical derivatives in the methanol, ethanol, acetone and $\mathrm{NaCl}$ aqueous solution extract were performed for standard photochemical screening.

\subsubsection{Detection of flavonoids}

Magnesium ribbon and few drops of concentrated HCL were added to $2 \mathrm{ml}$ of extracts in a test tube, pink or red color indicates the presence of flavonoids [31]

\subsubsection{Detection of carbohydrate}

Molish test: $2 \mathrm{ml}$ of Molish's reagent and $2 \mathrm{ml}$ of extracts were boiled and then few drops of sulfuric acid was added. A radish ring indicates the presence of carbohydrates [31].

\subsubsection{Detection of reducing sugar}

$5 \mathrm{ml}$ of extracts was added with $5 \mathrm{ml}$ of boiling Fehling solution for 2-5min. A brick red precipitate indicates the presence of reducing sugar [31].

\subsubsection{Detection of tannin}

$2 \mathrm{ml}$ of extracts was taken into a test tube and added few drops of $0.1 \%$ or $1 \mathrm{~m}$ ferric chloride. A blue black or greenish black coloration indicates the presence of tannin [31].

\subsubsection{Detection of saponins}

Foam test: $2 \mathrm{ml}$ of extract was shaken with $5 \mathrm{ml}$ of distilled water in a test tube. If foam persist for ten minutes which indicates the presence of saponins [32].

\subsubsection{Detection of anthraquinones}

$2 \mathrm{ml}$ of extracts with added $2 \mathrm{ml}$ of ammonium hydroxide solution. A bright pink color indicates the presence of anthraquinones [31].

\subsubsection{Detection of steroides}

$2 \mathrm{ml}$ of extract, $2 \mathrm{ml}$ of chloroform, $2 \mathrm{ml}$ of acetic acid and $1 \mathrm{ml}$ of concentrated sulfuric acid. A blue green indicates the presence of steroids [31]

\subsubsection{Detection of Alkaloides}

Wagner test: $2 \mathrm{ml}$ of extracted treated with few drops wagner"s reagent. Formation of brown or radish precipitate indicates the presence of alkaloids [32]

\subsubsection{Detection of Glycosides}

Modified Bronstrager's test: Extracts were treated with some $0.1 \%$ or $1 \mathrm{~m}$ ferric chloride solution and immerse in boiling water for 5 minutes. Then the mixture was cooled and adds equal volume of benzene. Then the benzene layer was separated into another test tube and treated with ammonia solution. Formation of rose pink color in the ammoniacal layer indicates the presence of anthranol glycosides [32].

\subsubsection{Detection of phytosterol}

$2 \mathrm{ml}$ extracts were treated with $5 \mathrm{ml}$ chloroform and filtrates. Then the filtrates were treated with few drops of concentrated sulfuric acid shaken and allowed to stand. Appearance of golden yellow color indicates the presence of phytosterol [32].

Libermanburchard's test: $2 \mathrm{ml}$ of extracts were treated with $5 \mathrm{ml}$ of chloroform and filtrates. Then added a few drops of acetic acid anhydride and boiled. Added few drops of concentrate sulfuric acid. Formation of brown ring at the function indicates the presence of phytosterol [32].

\subsubsection{Detection of Phenols}

Ferric chloride test: $2 \mathrm{ml}$ of extract were treated with $3-4$ drops of $0.1 \%$ or $1 \mathrm{~m}$ ferric chloride solution. Formation of bluish black color indicates the presence of Phenols [32].

2.3.12 Detection of Terpenoides: $2 \mathrm{ml}$ of extract were treated with $2 \mathrm{ml}$ of chloroform, then added $3 \mathrm{ml}$ of or few drops of sulfuric acid. Radish brown coloration in the inter face indicates the presence of terpenoides [33].

\section{RESULT AND DISCUSSION}

The present study carried out on the Musa paradisica plants and the Musa sapientum peels waste materials revealed the presence of medicinal and active compounds. The phytochemical active compounds of this materials were qualitatively analyzed from the four types of extracts such as methanolic, ethanolic acetone and the aqueous $\mathrm{NaCl}$ solution individually and the result are presented in Table 1 and Table 2 based on the color change indicate positive and negative results. In this screening process we were identified different types phytochemicals which has shown their activity in different solution.

Table 1: The analysis of phytochemicals in the various extracts of (Musa sapientum)

\begin{tabular}{llccc}
\hline Phytochemical & Methanol Extract & Ethanol Extract & Acetone Extract & Aqueous Extract \\
& + & + & + & - \\
\hline Flavonoids & + & + & - & - \\
Carbohydrates & + & + & + & + \\
Reducing Sugar & + & + & + & - \\
Tannins & + & + & + \\
Saponins & + & + & & - \\
\hline
\end{tabular}




\begin{tabular}{|c|c|c|c|c|}
\hline Anthraquinones & - & - & - & - \\
\hline steroids & - & - & - & - \\
\hline Alkaloids & + & + & + & - \\
\hline Glycosides & + & + & - & + \\
\hline Phytosterols & + & + & + & + \\
\hline Phenols & + & - & + & + \\
\hline Terpenoids & + & - & + & + \\
\hline
\end{tabular}

$+=$ presence; - = absence

Table 2: The analysis of phytochemicals in the various extracts of (Musa paradisica)

Phytochemical Methanol Extract $\quad$ Ethanol Extract Acetone Extract

\begin{tabular}{lcccc}
\hline Flavonoids & + & + & + & - \\
& + & + & - & + \\
Carbohydrates & - & + & - & - \\
Reducing Sugar & & & - & -
\end{tabular}

$\begin{array}{lcccc}\text { Saponins } & + & + & - & - \\ \text { Anthraquinones } & - & - & - & -\end{array}$

$\begin{array}{lcccc}\text { steroids } & - & - & - & - \\ & + & + & + & + \\ \text { Alkaloids } & + & - & + & + \\ \text { Glycosides } & + & - & + & + \\ \text { Phytosterols } & & + & + & + \\ \text { Phenols } & & + & +\end{array}$

$+=$ presence; - = absence

The present study carried out the Musa shapientum peels, and Musa paradisica plants revealed the presence of medicinal active constituents. Four types of solvents also used to determine the qualitative analysis of phytochemicals constituents. $70 \%$ methanol, ethanol, acetone and $0.9 \% \mathrm{NaCl}$ were used as a solvent for the determination time. Methanol, ethanol, acetone is suitable solvent for the analysis of phytochemicals. Though aqueous solvent like distilled water is universal solvent, we used $0.9 \% \mathrm{NaCl}$ solution as a solvent because $\mathrm{NaCl}$ solution acts as a normal saline. So, two types of samples and four types of solvents were analyzed one by one and identify the phytochemical constituents by observing color changes for detection part. Flavonoids, carbohydrates, reducing sugar, tannins, saponins, anthraquinones, steroids, alkaloids, glycosides, phytosterols, phenols and terpenoids, were detected in this study. Anthraquinones and steroids were totally absent in every types of extracts.

Secondary metabolites of Musa sapientum were qualitatively analyzed and the result has showed in table 1 . Musa paradisica result also included in table 2 . All the analyzed result is presented on that table based on the presence and absence of color change indicate the positive and negative results are indicating. Methanol, ethanol, and acetone gave a perfect color and result. Musa shpientum peels and Musa paradisica plants are called the waste products or waste biproducts which are available in Bangladesh. Even in food industry produces large amount of these types of waste both solid and liquid resulting from the production, processing and consumption of food. These waste pose increasing disposal and potential severe pollution problems and represent a loss of valuable biomass and nutrients. These byproducts and their pollution has hazard aspects in many cases, food processing waste might have a potential for conversion in to value added products. These types of waste like banana peels and banana plants waste are used for other purpose of isolation of phytochemicals compounds.

Phytochemicals are used in food industry as a flavouring agents, antioxidant, coloring agents and nutraceuticals agents. Flavonoids and carbohydrates are two types of phytochemicals which have various using purpose and easily get from this banana waste materials. Phytochemicals are used in food industry 
as food ingredients or food additives and physic-chemicals determine how they are used in industry. For example, if a phytochemical is an antioxidant activity and could be potentially used to avoid undesirable oxidation of food products (fat of protein) [34]. The use of phytochemicals in food industry is controlled by competent regulation body such as BSTI, BCSIR.

Flavonoids compounds are the sub group of polyphenols. Polyphenols, a secondary plant metabolites are most abundant antioxidants in human diets. These compounds are designed with an aromatic ring carring one or more hydroxyl moieties. Two main group of polyphenols termed flavonoids and nonflavonoids. Flavonones, flavones, dihydroflavonols, flavonols, flavan 3-ols, anthocyanidins, isoflavones, and proanthocynidins. Nowadays, there are a wide range of supplements rich in flavonoids from numerous plant extracts can be easily found. Some drink and beverage companies are using flavonoids to target the healthy products market. Large worldwide producers of soft drink and fizzy drinks have been launching variation of their existing products enriched with polyphenols [35].

Carbohydrates are one of the most important ingredients in foods and raw materials. They naturally added to food products to provide nutrients and improve the texture and overall quality of food products. In food industry carbohydrates using mandatory most of abundant carbohydrates in food products followed by pectin, hemicelluloses and cell wall materials. Many carbohydrates are also added to food system as stabilizer and dietary fiber. For example, production and processing of bread, biscuit items badly needed in using of carbohydrate compounds. Carbohydrates are quite heterogeneous and differing in primary structure degree of polymerization. Mono, oligo, and polysaccharides macromolecules are included in carbohydrate group. Carbohydrate constitute adverse nutrient category ranging from sugar easily digested by monastic animals in the small intestine to dietary fiber fermented by microbes in the large intestine. Polysaccharides are also used for stabilizing emulsions, foams, and gels in many cosmetic products [36].

Overall phytochemicas have a wide range of impacts on production of food and food products. Phytochemicals perform in food processing sectors as a coloring agents, antioxidant agents, stabilizer, foaming agents, gelling agents, antioxidant and antimicrobial activity to extend shelf life [37]. Extraction of phytochemical from such kind of waste or materials which are available and which produce huge amount of waste materials. Banana peels, and banana plants waste can be recycle for the isolation of important phytochemicals which are actually used for production of food products. Every year our food industry imported huge amount of phytochemicals based food additive from abroad. So it can be establish a waste biproducts processing industry in small scale, where the waste materials are processed and isolated phytochemicals for the further use of our food industry. As a result we can save huge amount of importing cost and waste free environment. After isolating phytochemicals from waste materials grinded and pestle sample biproducts can be used as a fertilizer in the field.

\section{CONCLUSION}

The present study were qualitatively analyzed some potential phytochemicals from popular waste banana peels and plants. Most of the phytochemicals are the essential raw materials for food and pharmaceuticals industries which are imported every year. Banana peels and plants are being wasted after consumption and collection of banana fruit. It has become a vital concern of environmental pollution. This two types of materials would be a great source of extraction of phytochemicals which are important raw materials for food and pharmaceuticals industry. Every year all over the world huge amount of phytochemicals are being imported by food and pharmaceuticals industries. Even Bangladesh imported such kind of phytocompound for their demand of raw materials of food industries. Phytochemicals isolation would be a great currency saving method by extraction and purification of some selected phytochemicals which actually needed for food and pharmaceuticals industries. So establishing an allied industry would be a better idea to isolation and purification of phytochemicals from this types of waste materials. At the same time it will be helps to reduce environmental pollution by using this waste materials. After purification this waste pose materials would be a suitable fertilizer for our agricultural land.

\section{ACKNOWLEDGEMENT}

The authors acknowledge their profound gratitude to the management of department of Nutrition and Food Engineering, Daffodil International University for providing the facilities for research work.

\section{REFERENCES}

[1] Sarkar, S.D., and Nahar, L. 2007. Chemistry for pharmacy students General, Organic and Natural Product Chemistry. England: John Wiley and Sons. Pp. 283-359.

[2] Abo, K.A., Ogunleye, V.O., and Ashidi, J.S. 1991. Antimicrobial potential of Spondias mombin, croton zambesicus and Zygotritonia crocea. Journal of Pharmacological Research. 5(13): 494-497.

[3] Liu, R.H., 2004. Potential synergy of phytochemicals in cancer prevention: mechanism of Action. Journal of Nutrition. 134(12):3479-3485

[4] Nweze, E.L., Okafor, J.l and Njoku O. 2004. Antimicrobial Activities of Methanolic extracts of Traumeguinesssis (scchumn and Thorn) and Morinda Lucinda used in Nigerian Herbal Medical practice, Journal of Biological Research and Biotechnology. 2(1): 34-46.

[5] Doughari, J.H., Human, J.S., Bennade, S. and Ndakidemi, P.A. 2009. Phytochemicals as chemotherapeutic agents and antioxidants: possible solution to the control of antibiotic resistant verocytotoxin producing bacteria. Journal of Medicinal Plants Research. 3(11): 839-848.

[6] Tiwari, B.K., Brunton, N.P., Brennan, C. 2013. Handbook of plant food phytochemicals: sources, stability and extraction. John Wiley and Sons, 1-4.

[7] Tiwari, B.K., Valdramidis, V.P. 2009. "Application of Nutritional Antimicrobials for Food Preservation “. Journal of Agricultural and Food Chemistry 57 (14), 5987-6000.

[7] Karakaya, S. Kavas, A. 1999. Antimutagenic Activities in some foods, Journal of Science of Food and Agriculture, 79(2), 237-242.

[8] Belitz, H.D., Grosch, W. 2004. Aroma compounds, Food chemistry. Springer, Berlin, Heidelberg, 342-408.

[9] Akhter, A. Zaman, S. Umar, M. Ali, M.Y., Ali, Jalil Miah, M.A. 2010. Isolation of Polyphenolic Compounds from the Green Coconut (cocos nucifera) Shell and Characterization of their Benzoyl Ester Derivatives. Journal of Science and Research. 2 (1), 186-190

[10] Schieber, A., Stintzing, F.C. 2001. "Byproducts of plant food processing as a source of functional compounds-recent debelopments "Trends in food science and technology 12 (11), 401-413.

[11] Cowan, M.M., 1999. Plant Products as Antimicrobial Agents. Clinical Microbiology Review, 12 (4) 564-582.

[12] Van V, Suliman, S.F.S., 2009. "The antimicrobial activity of four commercial essential oils in combination with conventional antimicrobials." Letters in Applied Microbiology, 48 (4), 440-446

[13] Monika. S, 2014. Antioxidant properties of extracts from selected plant materials (Caesalpinia spinosa, Perilla frutescens, Artemisia annua and Viola wittrockiana) in vitro and in model food systems, Universitat Politecnica De Catalunya, Barcelonatech. Pp.97-102

[14] Novak, F. J. 1992. Musa (Bananas and Plantains). In: Hammerschlag, F.A. and Litz., R.E. (eds), Biotechnology of Perennial Fruit Crops. CAB International, University Press, Cambridge. U.K. pp. 449-488. 
[15] Husain, M.D., and William, R. 2010. Status of banana cultivation and disease incidences in Malaysia. Crop Protection and Plant Quarantine Division, Department of Agriculture, Malaysia, Pp.: 60.

[16] FAO (Food and Agricultural Organization). 2004. Production Yearbook 2003, Rome, Italy

[17] Hossain, M.F., 2014, A STUDY OF BANANA PRODUCTION IN BANGLADESH: AREA, YIELD AND MAJOR CONSTRAINTS. ARPN Journal of Agricultural and Biological Science. . 9(6), 205-210.

[18] Haque M.A., 1988. Kolar Bagan (In Bengali). $3^{\text {rd }}$ Edition. Banana Research Project, Bangladesh Agricultural University, Mymensingh. p. 24.

[19] Mukul, A.Z.A., Rahman, A. 2013. Production and profitability of banana in Bangladesh-an economic analysis. International Journalof Economics, Finance and Management Sciences. 1(3): 159-165.

[20] Chung, S.L., and Meyers, S.P., 1979. Bioprotein from banana waste. Development in Industrial Microbiology, 20, 723-731.

[21] Krishna, C. 1999. Production of bacterial cellulose by solid state bioprocessing of banana waste. Bio resource Technology, 69, 231-239.

[22] Tchobanoglous, G., Theisen, H., and Vigil, S. 1993. Integrated solid waste management: Engineering principles and management issues. McGraw-Hill, New York, pp. 3-22.

[23] Zhang, P., Whistler, R.L., BeMiller, J.N., and Hamaker, B.R. 2005. Banana starch: production, physicochemical properties, and digestibility - a review. Carbohydrate Polymers, 59 (4), 443-458

[24] Larrauri, J.A., Ruperez, P. and Saura-calixto, F. 1999. New approaches in the preparation of high dietary fibre from fruit by-products. Trends in Food Science and Technology, 29, 729-733.

[25] Wolfe, K., Xianzhong, W.U., and Liu, R.H. 2003. Antioxidant activity of apple peels. Journal of Agricultural and Food Chemistry, 51, 609-614.

[26] Randy C.P., Angela K.K., Jeff D. and Scot C.N, 2007. Banana and plantain—an overview with emphasis on Pacific island cultivars, Species Profiles for Pacific Island Agroforestry, 1, Pp.2-27.

[27] Kanazawa, K. Sakakibara, 2000. H. High content of a dopamine, a strong antioxidant, in Cavendish banana. Journal of Agricultural and Food Chemistry, 48 (3), 844-848.

[28] Salawu, L., Bolarinwa, R.A., Adegunloye, A.B., and Moraine, H.A, 2010. HBs Ag, anti-HCV, anti-HIV and VDRL in blood donors: Prevalence and trends in the last three and a half years in a tertiary health care facility in Ile-Ife, Nigeria. International Journal of Medical Sciences 2(11): 335-341.

[29] Poonguzhali, P.K. and Cheju, H. 1994. The influence of banana stems extract on urinary risk factors for stones in normal and hyperoxaluric rats. British Journal of Urology, 74(1): 23-25.

[30] BBS. 2009-2010. Statistical Year Book of Bangladesh, Bangladesh Bureau of Statistics, Ministry of Planning, Govt. of the People's Republic of Bangladesh Dhaka Bangladesh.,

[31] Sumathy, V., 2011. In vitro bioactivity and phytochemical screening of Musa acuminata flower, Pharmacologyonline 2, 118-127.

[32] Prashant, T., 2011. Phytochemical screening and extraction: A review, Internationale pharmaceutica sciencia, 1, 98-106.

[33] Nasrabadi, M., Halimi, M., Nadaf, M. 2013. Phytochemical screening and chemical composition of extract of Muscari neglectum. Middle-East Journal of Science and Research 14, 566-569.

[34] Dillard, C.J., and German, J.B, 2000. Phytochemicals: nutraceuticals and human health. Journal of the science of food and agriculture, 80, 1744-1756.

[35] Fatemeh, S. R., Saifullah, R., Abbas, F. M. A. and Azhar, M. E, 2012. Total phenolics, flavonoids and antioxidant activity of banana pulp and peel flours: influence of variety and stage of ripeness. International Food Research Journal 19 (3): 1041-1046.

[36] Ashish B., Manish K., Panditand P.R, 2012. Amelioration of in-vivo Antioxidant Activity by Banana Extracts. International Journal of Pharmaceutical \& Biological Archives 3(1):157-161.

[37] Cui, S.W. 2005. Food carbohydrates: Chemistry, physical properties, and applications. CRC press, Taylor and Francis Group, USA, 62 (4), 392. 